\title{
PARTICULARITĂȚI DE DIAGNOSTIC ŞI TRATAMENT ALE CORPILOR STRĂINI ESOFAGIENI (MONEDE) LA COPIL - STUDIU CLINICO-STATISTIC
}

\author{
Corneliu Toader ${ }^{1,3}$, Miorița Toader ${ }^{2}$, Iolanda Cristina Vivisenco ${ }^{2,3}$ \\ ${ }^{1}$ Institutul Național de Neurologie şi Boli Neurovasculare, Bucureşti \\ ${ }^{2}$ Spitalul Clinic de Urgență pentru Copii ,, Grigore Alexandrescu“", București \\ ${ }^{3}$ Universitatea de Medicină şi Farmacie ,, Carol Davila “, Bucureşti
}

\begin{abstract}
REZUMAT
Scopul lucrării. Autorii realizează un studiu clinico-statistic asupra cazurilor de corpi străini esofagieni la copil, cu referire particulară la cazurile de monede ingerate, internate şi rezolvate în secția ORL a Spitalului Clinic de Urgență pentru Copii „Grigore Alexandrescu“, în perioada 01.01.2006 - 01.08.2007.

Material şi metodă. Studiu retrospectiv, cu interpretarea şi coroborarea datelor clinice şi paraclinice obținute în urma studiilor de caz.

Rezultate. Din totalitatea cazurilor de corpi străini, monedele au deținut cel mai mare procent; durata medie de spitalizare a fost de 2 zile; nu s-au înregistrat cazuri de complicații majore (perforații esofagiene, sângerare prin interceptarea unui vas mare, mediastinită); s-au consemnat şi situații particulare ce au necesitat o atenție specială.

Concluzii. Toate cazurile au fost abordate şi rezolvate prin endoscopie cu tub rigid; scurtarea intervalului de timp până la prezentarea la medicul ORL facilitează abordul terapeutic, scăzând dramatic riscul apariției complicațiilor; examenul radiologic, deşi esențial, poate oferi uneori informații incomplete, certitudinea diagnostică fiind asigurată doar de examenul endoscopic.
\end{abstract}

Cuvinte cheie: corpi străini esofagieni, monede, abord terapeutic, copil

\section{INTRODUCERE}

Corpii străini esofagieni (CSE) reprezintă una dintre urgențele majore ale specialității ORL pediatrice, atât prin consecințele obturării lumenului esofagian (denutriție, deshidratare), cât mai ales prin complicațiile redutabile pe care le pot produce: perforații esofagiene, mediastinită, sângerare prin interceptarea unui vas mare. Riscul producerii acestor complicații creşte proporțional cu fiecare zi de întârziere în diagnostic şi tratament (1).

De multe ori, corpii străini ingerați traversează esofagul fără probleme, grație mobilității şi distensibilității acestuia. Cauzele cele mai frecvente ale impactării corpilor străini la nivel esofagian sunt determinate de:

- dimensiunile mari (cazul monedelor),

- formele particulare (în special acela care prezintă margini ascuțite)
- modificări ale lumenului esofagian (cel mai frecvent stenoza esofagiană postcaustică) $(1,2)$.

La copii, monedele dețin cel mai mare procent din totalul corpilor străini ingerați (până la 75\%, conform unor statistici (3). Acest fapt s-ar putea explica prin:

- diametrul mare al monedelor comparativ cu cel al lumenului esofagian, în cazul copiilor,

- atracția deosebită exercitată de monede asupra copiilor - în special în cazul celor mai mici de 4 ani (obiecte mici, strălucitoare, zgomotoase, accesibile, uşor manevrabile).

\section{MATERIAL ŞI METODĂ}

Am realizat un studiu clinico-statistic asupra cazurilor de corpi străini esofagieni la copii, cu referire particulară la cazurile de monede ingerate, 
internate şi rezolvate în secția ORL a Spitalul Clinic de Urgență pentru Copii „Grigore Alexandrescu“ din Bucureşti.

Alegerea acestui studiu ne-a fost sugerată de numărul mare de corpi străini esofagieni ce s-au adresat secţiei noastre în perioada respectivă.

Studiul nostru a inclus 102 cazuri de corpi străini esofagieni, internate în perioada 01.01.2006 01.08.2007, 46 dintre acestea fiind cazuri de monede ingerate.

\section{REZULTATE}

În urma repartiției pe sexe s-a constatat o predominanță a sexului masculin $(60,8 \%)$ față de cel feminin $(39,2 \%)$ (rezultate comparabile cu datele din literatură). În ceea ce privește raportul băieți/ fete, în cazul particular al monedelor ingerate, acesta s-a păstrat aproape nemodificat (62\% băieți, $38 \%$ fete) (Fig. 1).

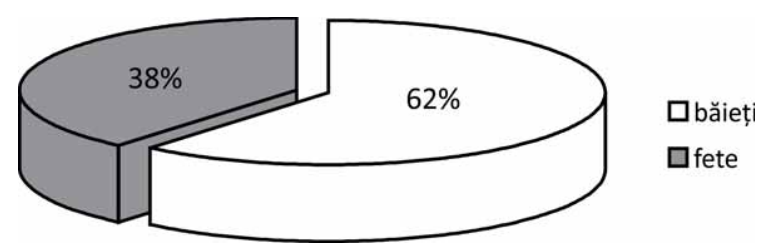

FIGURA 1. Distribuția pe sexe în lotul studiat

Pe perioada menționată, numărul de cazuri de CSE provenite din mediul urban a fost aproape dublu față de numărul de cazuri provenite din mediul rural (Fig. 2).

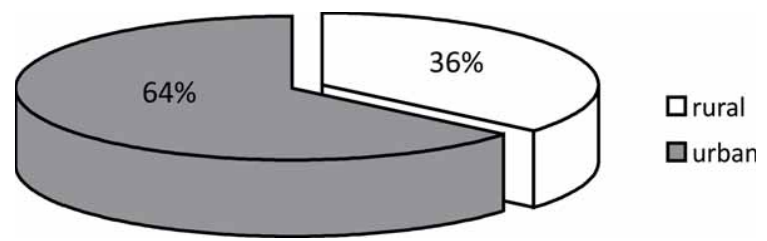

FIGURA 2. Distribuția pe medii de proveniență în lotul studiat

Am folosit următoarea clasificare pentru corpii străini:

- Monede

- Alte obiecte metalice (clame, agrafe, chei, capse etc.)

- Plastic (de obicei fragmente de jucării)

- Vegetali (sâmburi, paie, coji de fructe sau legume)

- Bol alimentar

- Oase.

Am considerat oportună următoarea separare a grupelor de vârstă: 0-1 an, 1-4 ani, 4-7 ani, peste 7 ani.
Rezultatele sunt prezentate în Tabelul 1 şi Fig. 3.

TABELUL 1. Clasificarea corpilor străini esofagieni

\begin{tabular}{|l|c|c|c|c|c|c|c|}
\hline $\begin{array}{l}\text { Grupe CSE } \\
\text { de vârsta }\end{array}$ & $\begin{array}{c}\text { mo- } \\
\text { nede }\end{array}$ & $\begin{array}{c}\text { alte } \\
\text { obiecte } \\
\text { metalice }\end{array}$ & $\begin{array}{c}\text { plas- } \\
\text { tic }\end{array}$ & $\begin{array}{c}\text { vege- } \\
\text { tal }\end{array}$ & $\begin{array}{c}\text { bol } \\
\text { ali- } \\
\text { mentar }\end{array}$ & oase & Total \\
\hline $0-1$ an & 0 & 2 & 2 & 0 & 0 & 1 & 5 \\
\hline $1-4$ ani & 37 & 5 & 7 & 8 & 2 & 2 & 61 \\
\hline $4-7$ ani & 6 & 1 & 5 & 3 & 4 & 1 & 20 \\
\hline$>7$ ani & 3 & 1 & 1 & 2 & 9 & 0 & 16 \\
\hline Total & 46 & 9 & 15 & 13 & 15 & 4 & 102 \\
\hline
\end{tabular}

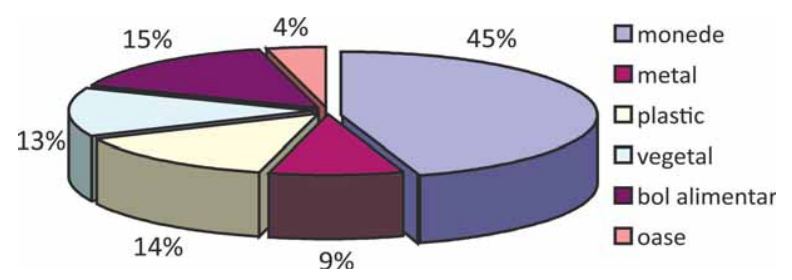

FIGURA 3. Clasificarea corpilor străini esofagieni în funcție de natura lor

În grupa de vârstă 0-1 an s-a înregistrat cel mai mic număr de CSE, fără a se consemna nici un caz de monedă.

Grupa de vârstă 1-4 ani a deținut primul loc în statistică din punct de vedere al numărului de cazuri din totalul CSE (61 din 102). În acest interval de vârstă, monedele au deținut cel mai mare procent din totalul cazurilor de CSE (Fig. 4). Din totalul cazurilor de monede pe întreg lotul de studiu, această grupă de vârstă (1-4 ani) deține ,recordul absolut" (80\%) (Fig. 5).

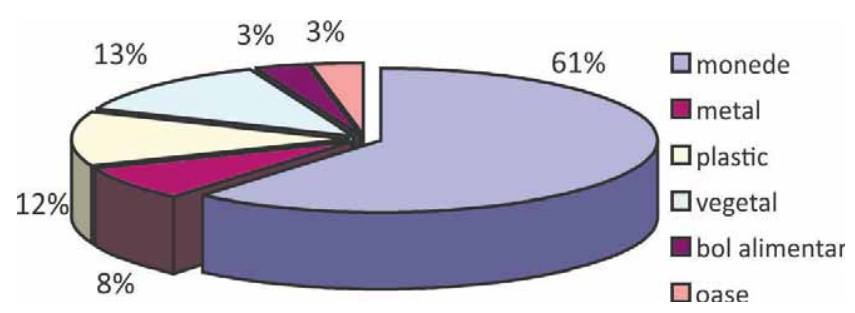

FIGURA 4. Distribuția procentuală a CSE la copii în grupa de vârstă 1-4 ani

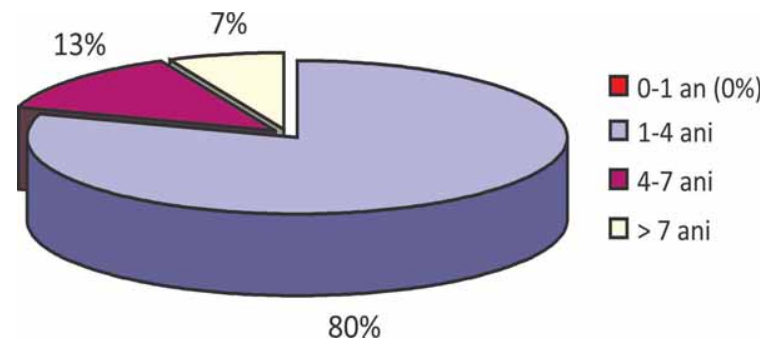

FIGURA 5. Distribuția procentuală a CSE pe grupe de vârstă

În intervalul 4-7 ani, constatăm că scade atât numărul total de cazuri de CSE (20 de cazuri), cât şi procentul de monede din totalul CSE ingerați în 
această grupă de vârstă (13\%). De menționat că 4 din cele 20 cazuri de CSE au fost diagnosticate la pacienți cunoscuți cu stenoză esofagiană postcaustică.

După vârsta de 7 ani, am constatat o importantă similitudine cu situația întâlnită la adulți (procentual, bolul alimentar deține primul loc, în special la copiii cunoscuți cu stenoză esofagiană postcaustică) iar numărul de monede este în scădere dramatică

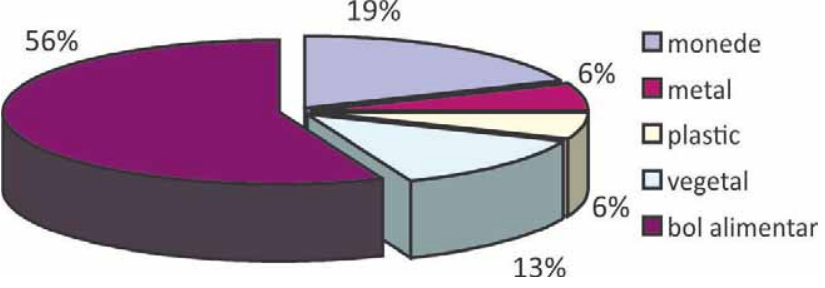

FIGURA 6. Distribuția procentuală a CSE la copii > 7 ani
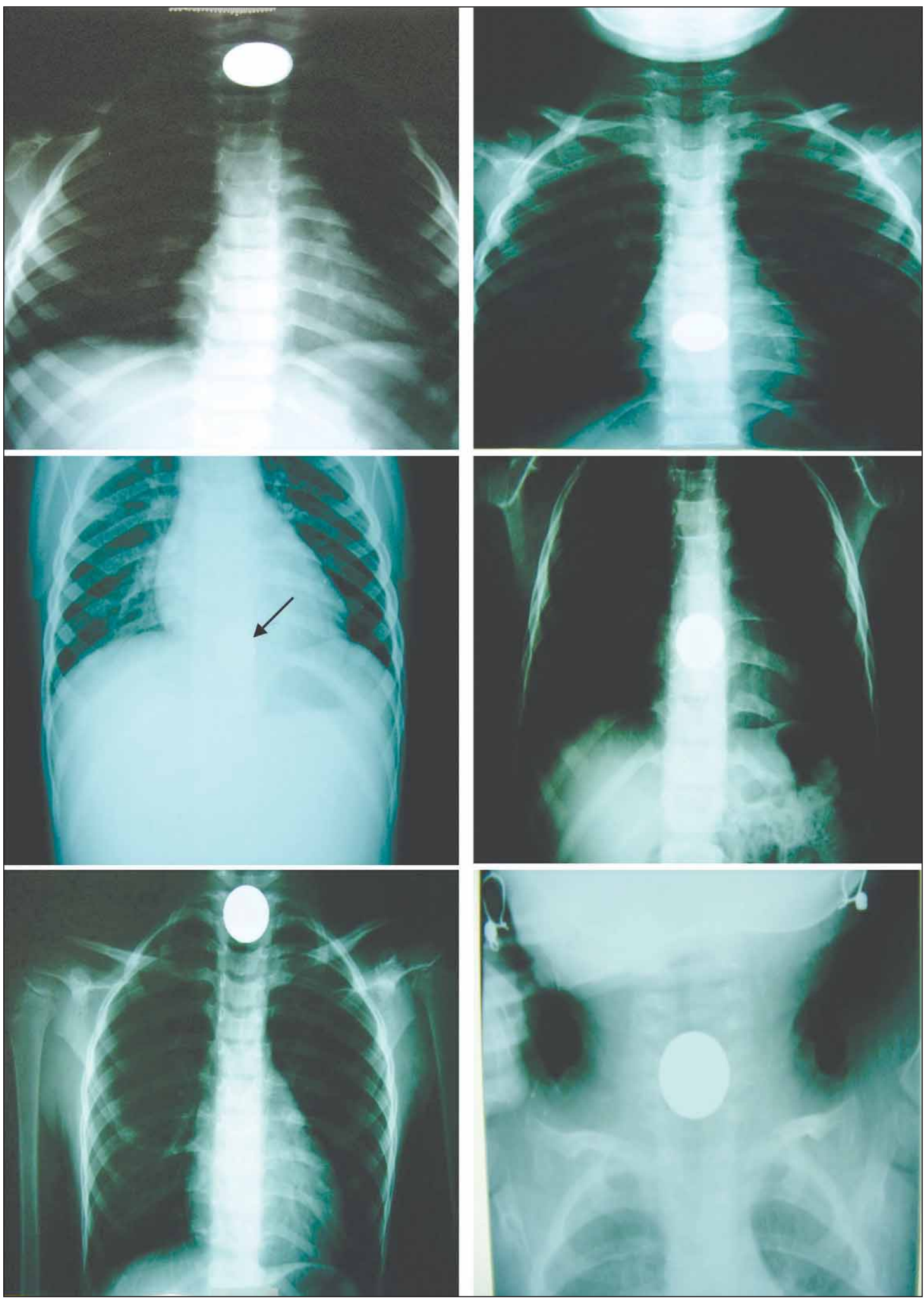

FIGURA 7.

Monede la

nivelul

esofagului -

examen

radiologic 
( 3 cazuri). De menționat că 5 dintre cele 16 cazuri de CSE s-au instalat la pacienți cunoscuți cu stenoză esofagiană postcaustică (Fig. 6).

Examenul radiologic efectuat la internare a pus în evidență prezența monedelor la nivel esofagian şi localizarea acestora, fiind absolut necesar pentru orientarea endoscopistului (Fig. 7). Menționăm situații particulare în care imaginea radiologică față şi profil a indicat prezența unei singure monede, „surpriza“ fiind relevată de endoscopie, care a evidenţiat într-un caz 3 monede de 1 ban, iar în celălalt 1 monedă de 50 bani şi 3 monede de 10 bani.

Prezentarea în secția de ORL s-a făcut relativ rapid în cazul monedelor (intervalul mediu fiind de aproximativ două zile de la ingestie). Am notat o singură excepție: un copil de 1 an şi 4 luni, din mediul rural, care s-a prezentat la 14 zile de la ingestie, cu stare generală deteriorată şi cu un grad ridicat de denutriție şi deshidratare.

$\mathrm{Nu}$ s-a înregistrat nici un caz de complicații majore (perforații esofagiene, mediastinită, sângerare prin interceptarea unui vas mare) - nici la prezentare în clinica noastră, nici în decursul manevrelor efectuate pentru extracția corpului străin (endoscopie cu tub rigid). Evoluția ulterioară a fost favorabilă, cu restabilirea rapidă a tranzitului esofagian.

Am consemnat însă câteva situații ce au necesitat o atenție specială:

- Moneda veche de 14 zile crease un important țesut de granulație, friabil, sângerând, îngreunând mult activitatea endoscopistului. Extracția s-a realizat cu dificultate, iar postoperator s-a instituit protecție antibiotică masivă până la revenirea la normal.

- Cele 2 cazuri la care radiografia de profil nu a reuşit să identifice corect numărul real de monede, acesta constituind o surpriză intraintervențională.

Toate cazurile de CSE au fost abordate endoscopic cu tub rigid. Deşi în literatură sunt descrise diverse metode non-endoscopice pentru îndepărtarea CSE (bujiraj cu împingerea corpului străin în stomac, utilizarea cateterului Foley etc.), fiecare dintre aceste metode prezintă un grad de risc, iar dacă sunt soldate cu insucces, abordul endoscopic ulterior pentru extracția CSE devine mult mai dificil $(4,5)$.

În 4 din cele 46 de cazuri de monede înghițite endoscopia nu a mai decelat prezența corpului străin, deoarece relaxarea produsă de anestezia generală a permis traversarea spontană a esofagului, cu confirmare radiologică ulterioară.
Durata medie de spitalizare în cazul monedelor a fost de 2 zile.

\section{DISCUȚII}

În studiul personal, grupa de vârstă 1-4 ani a înregistrat cel mai ridicat procent de CSE (61 de cazuri din 102) şi, totodată, cel mai ridicat procent al monedelor (37 din 46) comparativ cu celelalte grupe de vârstă. Explicația este oferită de tendinţa binecunoscută a acestei grupe de vârstă de a explora mediul înconjurător, inclusiv prin ducerea la gură a obiectelor, precum şi prin labilitatea psiho-motorie ce declanşează frecvente accese de plâns sau râs, ce facilitează înghițirea sau aspirarea corpului străin. În plus, copiii din această grupă de vârstă sunt atraşi de monede, datorită caracteristicilor acestora: strălucire, zgomot produs, accesibilitate, manevrabilitate uşoară.

Întârzierea prezentării la medic îngreunează considerabil manevrele de extracție datorită țesutului de granulație exuberant, friabil, sângerând, precum şi din cauza modificării (prin oxidare) a aspectului monedei - aceasta îşi pierde luciul şi îşi modifică culoarea, fiind mai dificil de reperat.

Examenul radiologic - deşi esenţial, poate oferi uneori informații incomplete, certitudinea diagnostică fiind asigurată doar de examenul endoscopic.

Endoscopia cu tub rigid rămâne metoda de elecție pentru rezolvarea acestei patologii la copil.

$\mathrm{Ne}-\mathrm{a}$ atras atenția predominanța netă a cazurilor din mediul urban. Intenționăm să urmărim acest aspect şi pe viitor, pentru a observa dacă putem lua în discuție un nou ,fenomen social": ritmul extrem de solicitant al vieții profesionale pentru tinerii părinţi şi numărul mare de ore alocat serviciului scad, implicit, timpul şi atenția acordate supravegherii copilului, acesta fiind, în consecință, mai expus la riscuri.

\section{CONCLUZII}

Considerăm că sunt necesare măsuri de educare a populației cu privire la gravitatea CSE la copil. Un aspect frecvent minimalizat de părinţi şi considerat ca fiind facil de rezolvat de către medic poate constitui, în realitate, un eveniment major, cu riscuri importante pentru micul pacient şi care solicită la maximum îndemânarea şi experiența specialistului. 